\title{
Cloning of the mouse agouti gene predicts a secreted protein ubiquitously expressed in mice carrying the lethal yellow mutation
}

\author{
Miles W. Miller, David M.J. Duhl, Harry Vrieling, ${ }^{1}$ Sabine P. Cordes, Michael M. Ollmann, \\ Ben M. Winkes, and Gregory S. Barsh \\ Department of Pediatrics and Howard Hughes Medical Institute, Stanford School of Medicine, Stanford, \\ California 94305-5428 USA; ${ }^{1}$ MGC Department of Radiation Genetics and Chemical Mutagenesis, \\ 2333 AL Leiden, The Netherlands
}

The mouse agouti gene controls the deposition of yellow and black pigment in developing hairs. Several dominant alleles, including lethal yellow $\left(A^{Y}\right)$, result in the exclusive production of yellow pigment and have pleiotropic effects that include obesity and increased tumor susceptibility. In an interspecific backcross, we established genetic limits for the agouti gene and found that the $A^{y}$ and the lethal non-agouti $\left(a^{x}\right)$ allele were not separated from a previously identified probe at the breakpoint of the Is1GsO chromosomal rearrangement. Using the Is1GsO probe, we isolated the agouti gene, and find that it has the potential to code for a secreted protein expressed in hair follicles and the epidermis, and that the level of expression correlates with the synthesis of yellow pigment. In the $A^{y}$ mutation, there is a chromosomal rearrangement that results in the production of a chimeric RNA expressed in nearly every tissue of the body. The $5^{\prime}$ portion of this chimeric RNA contains highly expressed novel $5^{\prime}$ sequences, but the $3^{\prime}$ portion retains the protein-coding potential of the nonmutant allele. We speculate that dominant pleiotropic effects of $A^{y}$ are caused by ectopic activation of a signaling pathway similar to that used during normal hair growth.

[Key Words: agouti; lethal yellow; coat color; obesity]

Received November 24, 1992; revised version accepted January 4, 1993.

Of more than 50 murine genes in which mutations have been recognized by their effects on coat color, several have proven of general interest because of their involvement in fundamental processes, such as cell migration or signaling (Geissler et al. 1988), or because of their pleiotropic effects on the hematopoietic (Huang et al. 1990), nervous (Epstein et al. 1991), or endocrine systems (Danforth 1927). One such gene is the mouse agouti locus, which controls the timing and the type of pigment deposition in developing hairs (for review, see Searle 1968; Silvers 1979).

The agouti phenotype results from the synthesis of a subapical band of yellow pigment, phaeomelanin, on an otherwise black, or eumelanic background, and is found in all strains of laboratory and wild mice that carry the $A$ allele. This banded pattern of pigment deposition occurs during a cycle of active hair growth as follicular melanocytes switch from synthesizing eumelanin to phaeomelanin, and then back to eumelanin (Galbraith 1964; Sakurai et al. 1975). Transplantation experiments in which melanocytes from one mouse are allowed to migrate into developing hair follices of another have demonstrated that the banded hair pattern is not determined by the agouti genotype of melanocytes but, instead, by the genotype of surrounding cells (Silvers and Russell 1955; Silvers 1958a,b). Thus, with regard to agouti, follicular supporting cells and melanocytes can be considered as complementary halves of an intercellular signaling pathway in which the agouti gene product emanates from nonmelanocytic cells of the follicular stroma.

There are $\geqslant 19$ distinct phenotypic classes of agouti mutations; alleles of several classes have arisen many times (Dickie 1969; Cattanach et al. 1987; Siracusa 1991). In general, recessive alleles such as non-agouti (a), lethal non-agouti $\left(a^{x}\right)$, non-agouti lethal $\left\langle a^{I}\right\rangle$, and extreme non-agouti $\left(a^{e}\right)$ are associated with the production of eumelanin but not phaeomelanin; in a wild-type background of other coat color markers, $a^{\mathrm{x}} / a$ and $a / a$ mice are mostly black, and $a^{l} / a^{e}$ or $a^{e} / a^{e}$ mice are completely black (Papaioannou and Mardon 1983; Lyon et al. 1985). Because the radiation-induced mutation $a^{l}$ (originally described as $a^{9 H}$; Cattanach et al. 1987) appears to be a large genomic deletion (Barsh and Epstein 1989b), the production of only eumelanin is probably an amorphic phenotype caused by the absence of a functional gene product. In contrast, dominant alleles, such as lethal yel- 
low $\left\langle A^{y}\right|$, are associated with excessive production of phaeomelanin; $A^{y} /$ - mice in a wild-type background of other coat color markers are completely yellow.

Besides affecting coat color, $A^{y}$ has pleiotropic effects that, except for embryonic lethality, are also dominant. These include increased susceptibility to a wide variety of spontaneous and chemically induced tumors (Heston 1942; Heston and Deringer 1947; Heston and Vlahakis 1961; Vlahakis and Heston 1963; Deringer 1970), insulin-resistant hyperglycemia (Carpenter and Mayer 1958; Hellerström and Hellman 1963; Wolff 1971), and adultonset obesity and increased somatic growth (Castle 1941; for review, see Herberg and Coleman 1977). Because the agouti gene product has not been characterized and because the molecular nature of the $A^{y}$ mutation has not been described previously, it has not been possible to determine whether the pleiotropic effects of $A^{y}$ are the result of the altered expression of genes other than those responsible for agouti coat color. $A^{y}$ was present in stocks derived from mouse fanciers, and the $A^{y}$ alleles in different strains of mice probably have a single origin (Morse 1981); in addition, several lines of evidence suggest that $A^{y}$ is pseudoallelic to other agouti locus alleles (Russell et al. 1963; Siracusa et al. 1987a).

An understanding of the agouti signaling pathway and the pleiotropic effects caused by $A^{y}$ would be greatly aided by isolation of the agouti gene. To this end, we have generated high-resolution physical, radiation hybrid, and meiotic maps surrounding agouti (Barsh and Epstein 1989a,b; Ollmann et al. 1992). In the course of this work, a radiation-induced chromosomal rearrangement, IslGsO, was described by another laboratory (Woychik et al. 1990) in which a breakpoint of the rearrangment was thought to interrupt agouti sequences. A genomic probe from the breakpoint was later found to detect molecular abnormalities in two agouti mutations (Bultman et al. 1991), and we have performed additional mapping and molecular studies with this probe leading to the cloning of the agouti gene. Here, we report that the coding sequence of the agouti gene predicts a novel secreted protein that exhibits an unusual pattern of expression. In addition, we find that the $A^{y}$ mutation is caused by juxtaposition of novel $5^{\prime}$ sequences to the protein-coding region of the normal agouti gene. This results in expression of a chimeric mRNA in nearly all tissues of the body.

\section{Results}

Genetic mapping of an agouti-associated molecular marker

Previous genetic mapping studies have placed the agouti locus between the insertion sites of two ecotropic proviruses, Emv-13 and Emv-15, that lie $\sim 5 \mathrm{cM}$ proximal to the Ada gene on mouse chromosome 2 (Siracusa et al. 1989). These studies were based on segregation of the $A$ and $a$ alleles among interspecific backcross progeny and recombinant inbred strains, and indicated the following gene order and distances: cen-Emv-13-1.6 $\pm 1.0 \mathrm{cM}-a-$
$0.6 \pm 0.4 \mathrm{cM}-E m v-15-3.6 \pm 1.6 \mathrm{cM}-$ Ada-tel. Applying this information to the positional cloning of agouti is not straightforward, however, because there may be a disparity between physical and genetic distances surrounding agouti (Barsh and Epstein 1989a), especially with regard to the $A^{y}$ allele. In genetic studies, $A^{y}$ did not recombine with $E m v-15$ in 1457 backcross progeny, indicating that $A^{y}$ was $<0.2 \mathrm{cM}$ distant from $E m v-15$ (upper $95 \%$ confidence limit) (Siracusa et al. 1987a, 1989). Compared with the $0.6 \pm 0.4 \mathrm{cM}$ that separates $a$ and Emv-15, these data might have suggested a gene order of $a-\mid A^{y}, E m v-$ 15). However, rare recombinants recovered between $A^{y}$ and $a^{x}$ indicated that $A^{y}$ lay proximal and was pseudoallelic to other agouti locus alleles (for summary, see Siracusa 1991).

Neither the Emv-13 nor the Emv-15 provirus appears to have caused an agouti mutation, although the Emv-15 provirus is very closely associated with the $A^{y}$ allele (Copeland et al. 1983; Lovett et al. 1987; Siracusa et al. $1987 \mathrm{~b})$. To investigate the genetic relationship of $A^{y}$ and other agouti alleles to Emv-15, and to generate a highdensity meiotic map as a tool for the cloning of agouti, we established an intersubspecific backcross between Mus castaneus mice that carry the $A$ allele and laboratory mice carrying either the $A^{y}$ or $a^{x}$ allele. In a total of 127 backcross progeny that were typed for a series of four DNA markers between Emv-13 and Ada, there were eight recombinants (Table 1; data not shown); an additional 197 animals were typed only for agouti and Emv15. We found one recombinant between $A^{y}$ and Emv-15, and one recombinant between $a^{X}$ and the Emv-13 insertion site (Table 1; Fig. 1). These results demonstrate that $A^{y}$ lies proximal to Emv-15 and provide genetic limits within which the agouti gene must lie.

Woychik et al. (1990) described a radiation-induced chromosomal rearrangement, Is1GsO, in which an animal that was doubly mutant for limb deformity $(1 d)$ on proximal chromosome 2 and agouti on distal chromosome 2 was found to carry an inversion. Bultman et al. (1991) showed that a probe from the distal inversion breakpoint detected a small genomic deletion from a methylnitrosourea (MNU)-induced agouti mutation, $a^{5 M N U}$, which suggested that the inversion breakpoint lay close to the agouti gene and that the sequences deleted from the $a^{5 M N U}$ allele might be required for expression of the agouti gene. However, studies of the agouti suppressor allele $\left(A^{S}\right)$ indicate that agouti expression can be affected by genetically separable cis-acting sequences (Phillips 1966). To determine where the IslGsO sequences mapped relative to the genetic limits defined in our backcross, we used a probe from a cosmid that contained the Is $1 \mathrm{GsO}$ distal inversion breakpoint (probe $\mathrm{e}$ in Fig. $2 B$ ) to analyze the recombinant progeny from our backcross. In both the $A^{y}-E m v-15$ and the Emv-13-a recombinant, fragments detected by this probe cosegregated with agouti (Fig. 1). These results confirmed that the Is1GsO breakpoint mapped very close to the agouti locus (Woychik et al. 1990) and suggested that adjacent sequences might provide molecular access to the agouti gene (Bultman et al. 1991). 
Table 1. Segregation and recombination of Emv-13, Emv-15, and the agouti alleles $\mathrm{A}^{\mathrm{y}}$ or $\mathbf{a}^{\mathrm{x}}$ in backcross progeny between laboratory mice $\left(\mathrm{A}^{\mathrm{y}} / \mathrm{a}^{\mathrm{x}}\right)$ and $\mathrm{M}$. castaneus $(\mathrm{A} / \mathrm{A})$

\begin{tabular}{|c|c|c|c|c|c|}
\hline \multirow[b]{2}{*}{ Mice } & \multicolumn{3}{|c|}{ Inheritance of $M$. castaneus allele $\mathrm{e}^{\mathrm{a}}$} & \multicolumn{2}{|c|}{ Number of progeny } \\
\hline & Emv-13 & $A$ & $E m v-15$ & from $A^{y} / A$ parent & from $a^{x} / A$ parent \\
\hline \multirow[t]{4}{*}{ Parental } & + & + & + & 32 & 29 \\
\hline & - & - & - & 30 & 34 \\
\hline & N.D. & + & + & 58 & 52 \\
\hline & N.D. & - & - & 40 & 47 \\
\hline \multirow[t]{4}{*}{ Recombinants } & + & - & - & 0 & 1 \\
\hline & - & + & + & 0 & 0 \\
\hline & + or N.D. & + & - & 0 & 0 \\
\hline & - or N.D. & - & + & 1 & 0 \\
\hline $\begin{array}{l}\text { Recombination } \\
\text { frequency }^{\mathrm{b}}\end{array}$ & & & & $\begin{array}{r}\mid E m v-13, \\
\mid E m v-13, E m v \\
\mid A, E m v-1\end{array}$ & $\begin{array}{l}126=0.79 \pm 0.78 \\
2 / 127=1.57 \pm 1.1 \\
324=0.31 \pm 0.31\end{array}$ \\
\hline
\end{tabular}

$\mathrm{F}_{1} A^{y} / A$ or $a^{x} / A$ animals were backcrossed with MWT/Le laboratory mice homozygous for the $a^{t}$ allele.

${ }^{\mathrm{a}} A^{y} / a^{t}, a^{x} / a^{t}$, and $A / a^{t}$ animals can be distinguished by their coat color; $E m v-13$ and $E m v-15$ alleles were scored as shown in Fig. 1. Inheritance of agouti and Emv-15 was scored on 324 backcross progeny; inheritance of $E m v-13$ was also scored on 126 of these animals. ${ }^{b}$ Recombination frequencies are calculated according to Green (1981); the single recombinant between $A$ and EmV-15 was assumed to be nonrecombinant between $E m v-13$ and $A$.

\section{Identification of transcriptional units} in the region of the Is 1 GsO breakpoint

To isolate the agouti gene, we first generated an overlapping set of cosmids (contig) of $\sim 60 \mathrm{~kb}$ (Fig. 2A) starting with a cosmid, cos 12, kindly provided by Bultman et al. (1991). A series of unique-sequence probes were isolated from this contiguous sequence (Fig. 2B) and used to search for transcribed sequences by hybridization to Northern blots. Besides the gene responsible for agouti coat color, the presence of additional, closely linked genes has been inferred from complementation analysis of recessive lethal agouti alleles (Russell et al. 1963; Lyon et al. 1985; Barsh and Epstein 1989b|. Furthermore, the pleiotropic effects of $A^{y}$ are likely to be caused by expression of a gene or genes in a tissue other than the skin. Therefore, as a source of RNA for Northern hybridization experiments, we focused on skin taken from animals that carried the $A^{y}, A^{w}$, or $A$ alleles during a cycle of active hair growth and on tissues from several different organs in $A^{y}$ animals.

Using hybridization probes b, c, and d (Fig. 2B), we detected two RNAs of $\sim 0.8$ and $6.1 \mathrm{~kb}$ on Northern blots (Fig. 3; see also Fig. 6, below). Probes b and d detected the 0.8-kb RNA in skin and in testes from $A / A$ and $A^{y} / a^{x}$ animals; both probes also detected the $6.1-\mathrm{kb}$ RNA but only in testes (described further below). Probe $c$ detected the $6.1-\mathrm{kb}$ but not the $0.8 \mathrm{-kb}$ RNA. Using RNA from neonatal $A / A$ mice as a substrate for both conventional cDNA cloning and the enzymatic amplification of cDNA ends by the polymerase chain reaction (PCR), we isolated and sequenced $12 \mathrm{cDNA}$ clones for the $0.8-\mathrm{kb}$ RNA. Nine of these clones were very similar and represent a 730-nucleotide RNA not including poly(A) sequences (Fig. 2E); the remaining three clones were similar at the $3^{\prime}$ end but had different $5^{\prime}$ ends /data not shown). From a testes cDNA library, we also isolated a partial cDNA, $2.1 \mathrm{~kb}$ in length, that contains a poly(A) tail and represents the $3^{\prime}$ end of the 6.1-kb RNA, which is referred to as 0252 (Fig. 2C).

Hybridization and partial sequence analysis of genomic DNA from the cosmid contig (Fig. 2A) allowed us to determine the exon-intron structure and orientation of both cDNAs. The 730-bp cDNA contains four exons of $111,170,65$, and $384 \mathrm{bp}$, and covers $\sim 40 \mathrm{~kb}$ of genomic DNA (Fig. 2C-E). Exon 1 maps $\sim 20 \mathrm{~kb}$ away from exon 2 ; exons $2-4$ are clustered together within $6.2 \mathrm{~kb}$ of genomic DNA. Therefore, most of the gene's length is accounted for by the first intron (Fig. 2C). The $0252 \mathrm{cDNA}$ has a transcriptional orientation opposite that of the 730bp cDNA and contains at least three exons interspersed with exons 3 and 4 from the 730-bp cDNA (Fig. 2D; data not shown). On the basis of the sequence, structure, and expression pattern of the 730-bp (described below) and the 0252 cDNAs (data not shown), we concluded that the 730-bp cDNA represents the gene responsible for agouti coat color, and we therefore refer to it subsequently as the $A \mathrm{cDNA}$ and as originating from the agouti gene. The function of the $6.1-\mathrm{kb}$ mRNA is not yet known.

\section{cDNA structure of the agouti gene isolated from A/A animals}

The first ATG in exon 2 of the $A$ cDNA, at position 122 of the cDNA sequence (Fig. 2E), matches the consensus for vertebrate translational initiation regions (Kozak 1989|. Conceptual translation from this ATG yields a 131 -amino-acid protein of $\sim 16 \mathrm{kD}$. Within the first exon of the $A$ cDNA sequence, there are also ATGs at positions 8,21 , and 88 that mark open reading frames (ORFs) of 23,25 , and 43 amino acids, respectively, but none of these ATGs lie within a region predicted to function as a translational initiation site.

The predicted $16-\mathrm{kD}$ protein product of agouti can be 
A

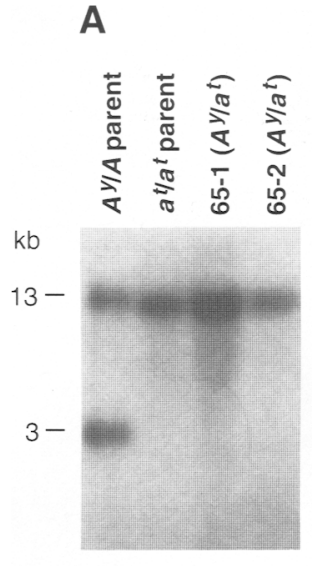

Emv-13 probe

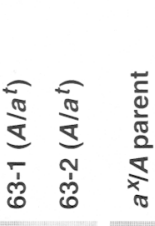

B
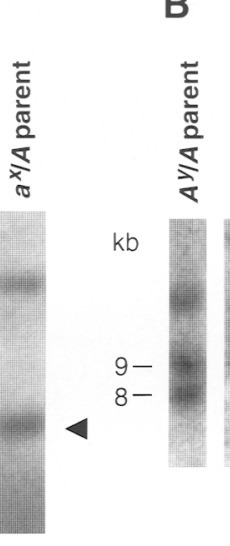

GsO probe
C

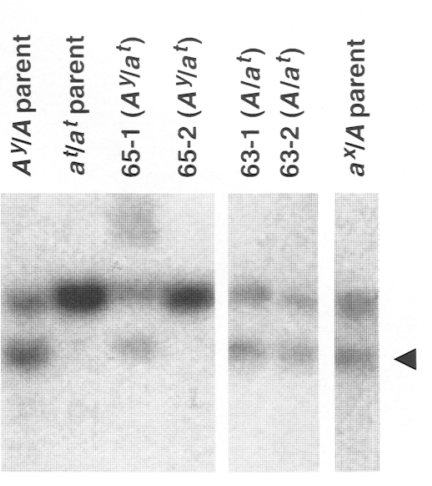

Emv-15 probe

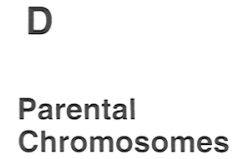

Recombinant Chromosomes<smiles>c1ccc2c(c1)CCC21CC2CCCC2C1</smiles>
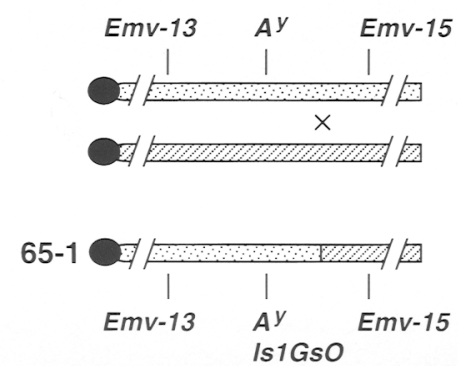
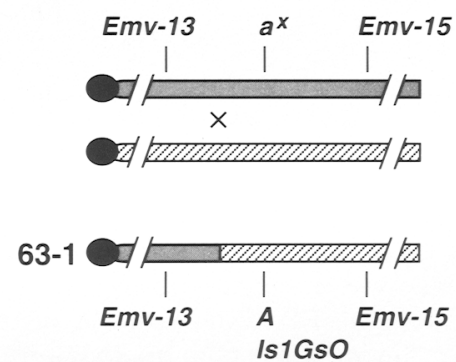

Figure 1. A probe from the distal IslGsO breakpoint maps between Emv-13 and Emv-15 among intersubspecific backcross progeny segregating the agouti alleles $A^{y}, a^{x}$, and $A$. A total of 161 progeny from the cross $A^{y} / A \times a^{t} / a^{t}$ and 163 progeny from the cross $a^{x} / A \times a^{t} / a^{t}$ were typed for the segregation of agouti and $E m v-15$; a subset of these 162 progeny from the cross $A^{y} / A \times a^{t} / a^{t}$, and 64 progeny from the cross $\left.a^{x} / A \times a^{t} / a^{t}\right)$ were also typed for Emv-13. (A) The Emv-13 probe detects a 3-kb TaqI fragment in $M$. castaneus $(A / A)$ mice and a $13-\mathrm{kb}$ TaqI fragment in laboratory mice $\left(A^{y}, a^{x}\right.$, or $\left.a^{t}\right)$. Animal 63-1 is a recombinant between $E m v-13$ and $A ;$ animal 63-2 is its nonrecombinant sibling. (B) The Is 1 GsO probe (probe e in Fig. 2B) detects an 8-kb BamHI fragment in $M$. castaneus $(A / A)$ mice and a 9-kb BamHI fragment in laboratory mice $\left(A^{y}\right.$ and $\left.a^{t}\right) .(C)$ The Emv-15 probe detects a 2.6-kb TaqI fragment in $M$. castaneus $(A / A)$ mice and a 3.4-kb TaqI fragment in laboratory mice $\left(A^{y}, a^{x}\right.$, or $\left.a^{t}\right)$. Animal 65-1 is a recombinant between $A^{y}$ and $E m v-15$; animal 65-2 is its nonrecombinant sibling. Arrowheads highlight the $M$. castaneus-specific fragments. $(D)$ Diagram of parental and recombinant chromosomes. In both animal 63-1 (recombinant between Emv-13 and $A$ ) and 65-1 (recombinant between $A^{y}$ and $E m v-15$ ), the Is $1 \mathrm{GsO}$ probe cosegregates with agouti.

divided into three domains (Fig. 2F) but is not similar to any peptide or conceptually translated nucleic acid sequence in the GenBank or EMBL data bases. The first domain of 22 amino acids, encoded for entirely on exon 2 , is very hydrophobic and has the characteristics of a eukaryotic signal sequence (von Heijne 1985, 1986). The second domain of 63 amino acids-encoded for on the remainder of exon 2, all of exon 3, and part of exon 4 -contains a potential amino-linked glycosylation site at amino acid residue 39 and a large proportion of basic amino acid residues (18/63). The carboxy-terminal third domain is encoded for on the remainder of exon 4 and contains a large proportion of cysteine residues (10/46).

Expression of the agouti gene from alleles $\mathrm{A}, \mathrm{A}^{\mathrm{w}}$, and $\mathrm{A}^{\mathrm{y}}$

The $A$ cDNA was used as a probe to investigate the re- lationship of its expression to phaeomelanin synthesis. As described above, the genetic relationship among different agouti alleles predicts that expression of the agouti gene product should positively regulate phaeomelanin synthesis. To determine whether a component of this regulation might involve gross alterations in the amount or structure of agouti mRNA, we used a portion of the 730-bp $A$ cDNA as a Northern hybridization probe to examine neonatal and adult $A^{W} / A^{W}$ skin and neonatal $A^{y} / a^{x}$ and $A / A$ skin during a cycle of active hair growth. The $A^{W}$ allele, white-bellied agouti, produces a "normal" agouti phenotype in dorsal skin, but in ventral skin the band of phaeomelanin is greatly expanded such that almost the entire hair is yellow. We found that the $A$ cDNA probe detects more RNA in ventral than in dorsal skin of adult $A^{W} / A^{W}$ mice (Fig. 3). In dorsal skin, the probe also detects increasing amounts of RNA during the switch from eumelanin to phaeomelanin synthesis that 

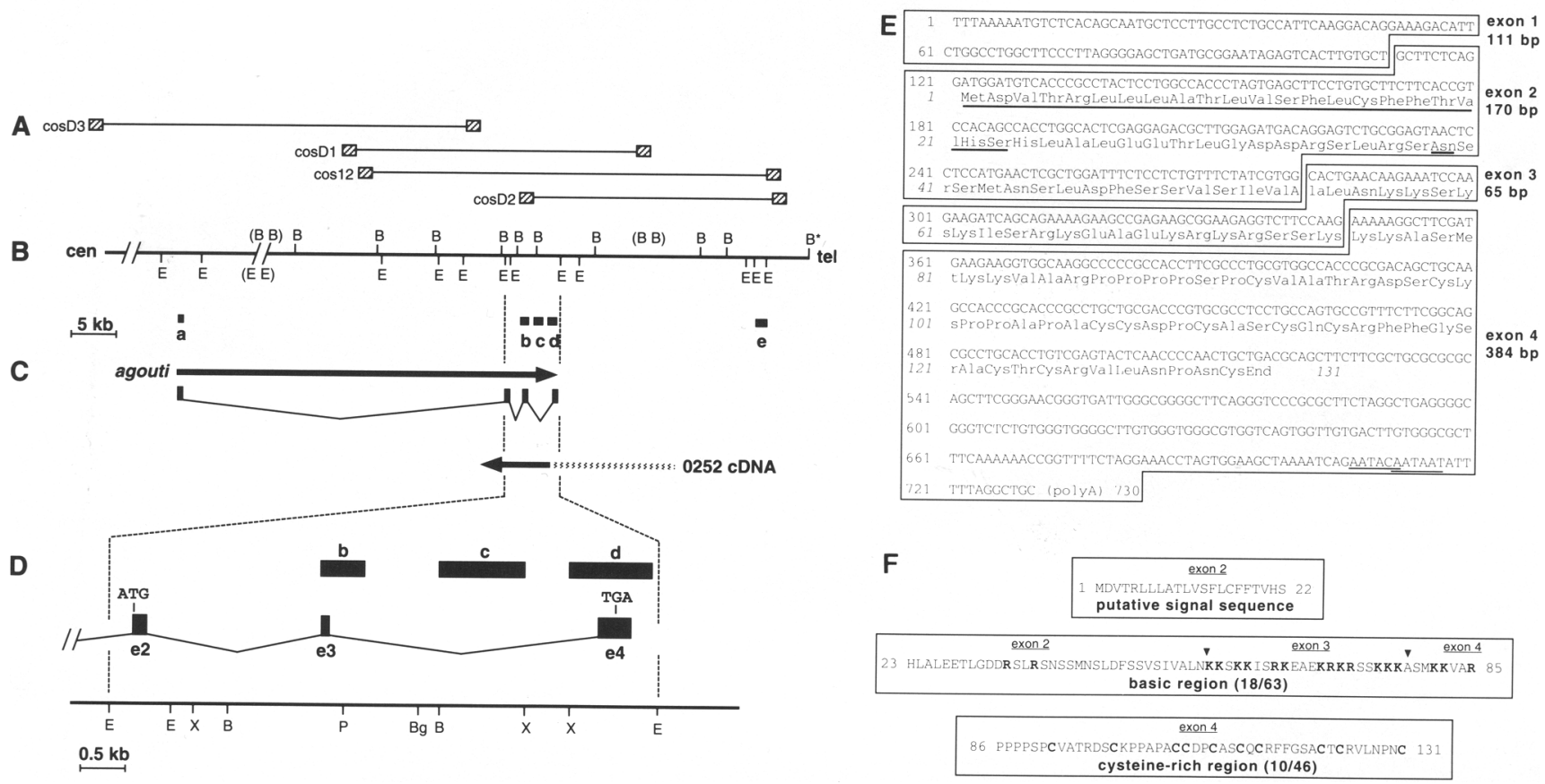

Figure 2. Physical, genomic, cDNA, and predicted protein structure of the agouti gene. $(A)$ Cosmid contiguous sequence used to identify and map the agouti gene. The agouti allele of origin for these cosmids is $\cos \mathrm{D} 3, A^{y}$ or $a^{x} ; \cos \mathrm{D} 1, A^{y} ; \cos 12, A^{w}$; and $\cos \mathrm{D} 2$, $A^{y}$. The restriction map was oriented with respect to the centromere by comparison with the Is $1 \mathrm{GsO}$ distal inversion breakpoint (Bultman et al. 1991). (B) BamHI (B) and EcoRI (E) restriction map of the contiguous sequence, and probes (a-e) used to identify and study the agouti gene. The $\mathrm{B}^{\star}$ site is not present within the contig but has been mapped in genomic DNA by Southern hybridization. Probe a is an 111-bp PCR-derived fragment that represents exon 1 of the agouti gene (see below). Probes b-d are described in Materials and methods. Probe e is a $1.3-\mathrm{kb}$ EcoRI genomic fragment that does not detect either the agouti or the 0252 RNA. (C) Genomic structure and transcriptional orientation of the agouti and the 0252 RNAs. Exons were mapped by hybridizing cDNA fragments to cloned genomic DNA; these locations were then confirmed, and the exon-intron borders were determined precisely by DNA sequencing. The $0252 \mathrm{cDNA}$ clone is $2.1 \mathrm{~kb}$ long and represents the $3^{\prime}$ end of a $6.1-\mathrm{kb}$ RNA expressed in testes. Both the $5^{\prime}$ end and at least two exons of the 0252 cDNA lie between exons 3 and 4 of agouti; additional sequences presumed to lie farther centromere-distal are depicted as broken lines. $(D)$ The location of agouti exons $2-4$ as determined by restriction mapping and sequence analysis of genomic DNA. Restriction sites are indicated for BamHI (B), EcoRI (E), BglII (Bg), PstI (P), and XbaI (X). Exons 3 and 4 lie within a 5.5-kb EcoRI fragment that, as described by Bultman et al. (1991), contains the IslGsO inversion breakpoint. (E) Complete nucleotide and predicted amino acid sequence of the 730-bp agouti cDNA. Two sequence variants not shown are described in Materials and methods. There is a 131-amino acid ORF that begins at nucleotide position 122 and a preceding stop codon in the same frame at nucleotide position 86. This predicted translational start, AGGATGGAT, contains a G at +4 and an A at -3 and therefore conforms exactly to the consensus for vertebrate translational initiation regions (Kozak 1989). Potential polyadenylation signals at the 3' end of the cDNA sequence are underlined. The sizes and locations of all four exons are also indicated. The GenBank accession number for this sequence is L06451. $(F)$ Potential agouti protein-coding sequence divided into three domains. The first domain is a putative signal sequence as defined by von Heijne $(1985,1986)$ and is underlined in $E_{\text {; }}$ the second domain contains a potential amino-linked glycosylation site at amino acid residue 39 (underlined in $E$ ) and a high proportion of Arg and Lys residues indicated in boldface type; the third domain contains a high proportion of Cys residues, also indicated in boldface.

occurs in a regenerating agouti hair bulb between days 5 and 6 after plucking (Fig. 3A) or in a newborn hair bulb between days 3 and 6 after birth (Movaghar and Hunt 1987; Granholm et al. 1990b).

In 3-day-old neonates, the $A$ cDNA probe detects increased amounts of RNA in the skin of $A^{y} / a^{x}$ animals compared with $A / A$ animals (Fig. 3A). In addition, the size of the $A^{y}$ RNA appears larger than the $A$ RNA by $\sim 100$ nucleotides (Fig. 3A). This size difference is not a function of the type of melanin being synthesized but, instead, is specific to the $A^{y}$ allele (see below).

We also examined the expression of agouti sequences from the $A^{W}$ and $A^{y}$ alleles by in situ hybridization during hair bulb regeneration. Skin sections harvested at days $3,5,7$, and 9 days after plucking were hybridized with either a 270-nucleotide antisense or control sense probe that contains coding and $3^{\prime}$-untranslated regions of the $A$ cDNA. At 7 days after plucking, $A^{W}$ follicles actively synthesize phaeomelanin, and the antisense probe detects expression in hair follicles and the nonkeratinized epidermis (Fig. 4A). The expression in hair follicles is generalized and appears to include the dermal papillae, the inner and outer root sheaths, and the hair cortex. Expression within epithelial cells of the hair follicle is continuous with the epidermis and appears to include basal and suprabasal cells. There is no expression detectable in the extrafollicular dermis.

Surprisingly, the pattern of expression detected by the 


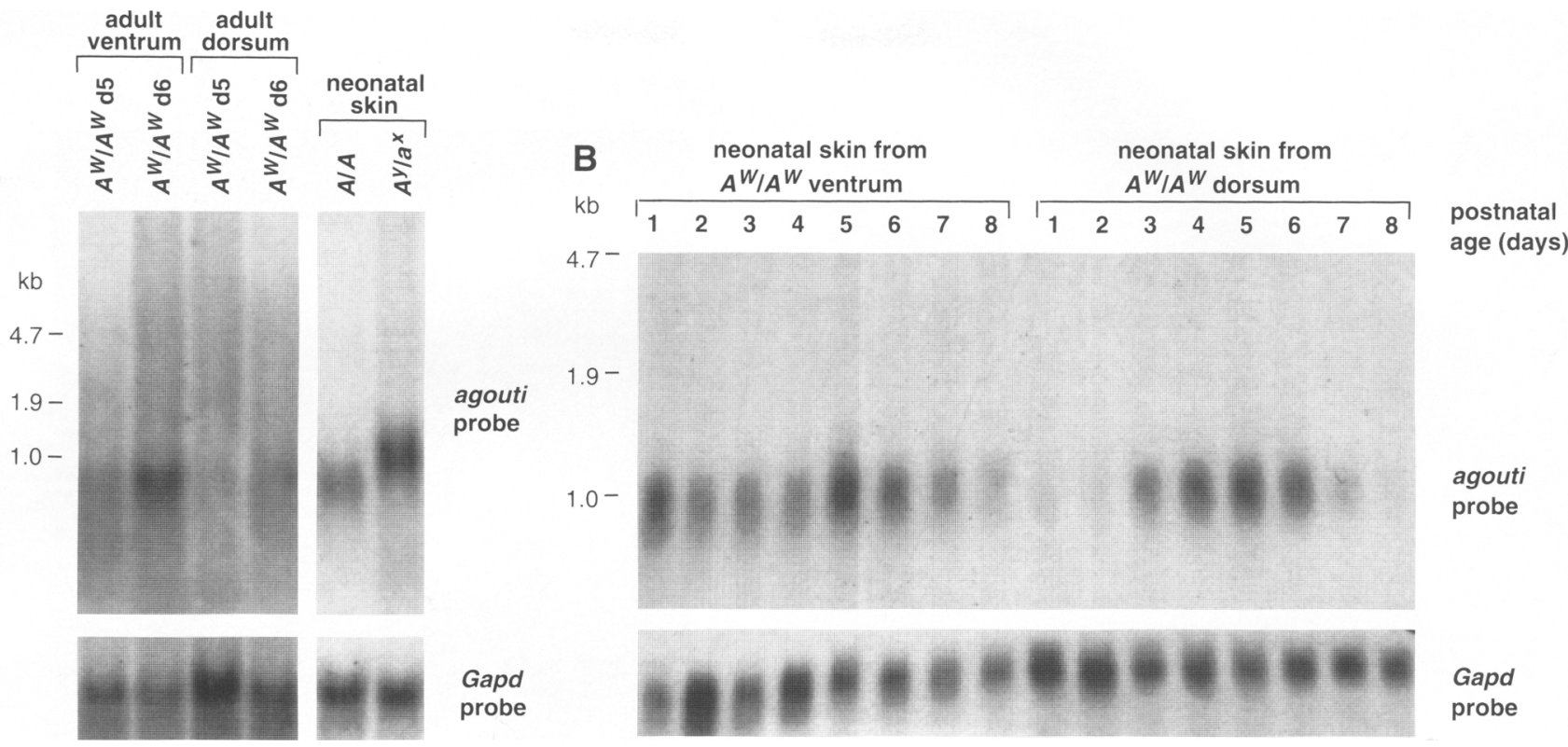

Figure 3. Expression of agouti detected by Northern hybridization of skin RNA from $A^{w} / A^{w}, A / A$, and $A^{y} / a^{x}$ mice. Total RNA was isolated from the dorsum and ventrum of $A^{W} / A^{W}$ adult skin at days 5 and 6 after plucking $(A)$, from $A / A$ and $A^{y} / a^{x}$ neonatal skin 5 days after birth $(A)$, and from $A^{W} / A^{W}$ neonatal skin at days 1-8 after birth $(B)$. The RNA was fractionated on a formaldehyde-agarose gel, transferred to a nylon membrane, and hybridized with a PCR-generated agouti-coding region probe (nucleotides 284-696 of Fig. 2E). The lower panels depict hybridizations with a Gapd "housekeeping" probe to control for different amounts and quality of the RNA loaded on the gels. (A) A duplicate membrane to that used in the upper panel was used to generate the autoradiograph shown in the lower panel; $(B)$ the same membrane hybridized with the agouti-coding region probe was rehybridized with the Gapd probe to generate the autoradiograph shown in the lower panel.

$A$ antisense probe in skin from $A^{y} / a^{x}$ animals is grossly similar to that detected from $A^{W} / A$ animals (Fig. 4B). However, it was our impression that there was reduced expression in the base of $A^{y}$ hair follices compared with the base of $A^{W}$ hair follicles, at the approximate location of the dermal papillae (arrowheads; Fig. 4B). In addition, the relative intensity of agouti expression appeared higher in skin from $A^{y} / a^{x}$ animals than from $A^{W} / A$ animals and did not vary between days $3,5,7$, and 9 after plucking. In contrast, the level of agouti expression in skin from $A^{W} / A$ animals was apparently higher at days 5 and 7 than at days 3 and 9 after plucking (data not shown).

\section{cDNA and genomic structure of the agouti gene} isolated from $\mathrm{A}^{\mathrm{y}} / \mathrm{a}^{\mathrm{x}}$ animals

To investigate possible structural differences between the $A^{y}$ and the $A$ alleles, we cloned an $A^{y}$-specific cDNA. Because $A^{y} / A^{y}$ embryos die around the time of implantation (Eaton and Green 1962; Papaioannou 1988), it was not possible to use a tissue for cDNA cloning that contained only the $A^{y}$ allele. However, when the $A$ cDNA was hybridized to RNA from different tissues of $A^{y} / a^{x}$, $a^{x} / a$ and $a / a$ animals, a band of $\sim 0.9 \mathrm{~kb}$ was detected in many tissues of $A^{y} / a^{x}$ animals (see Fig. 6), but no signal could be detected from $a^{x} / a$ and $a / a$ tissues except for the testes (data not shown). Therefore, we expected that any cDNA clone isolated from $A^{y} / a$ or $A^{y} / a^{x}$ animals would originate from the $A^{y}$ allele, and we used the skin of neonatal $A^{y} / a^{x}$ animals as a source for cDNA. Of 17 clones that were isolated and sequenced, 6 represented the 730-nucleotide RNA of the $A$ allele described above (see Fig. 2E). Ten clones, however, were similar in their $3^{\prime}$ portions to the $A$ allele but contained novel $5^{\prime}$ portions specific for the $A^{y}$ allele; we describe these clones subsequently as representative of the $A^{y}$ cDNA (Fig. 5A). The remaining clone contained a $3^{\prime}$ portion similar to the $A$ allele but a $5^{\prime}$ portion that was different from both other classes (data not shown).

The $A^{y}$ cDNA represents a 923-nucleotide RNA, not including poly(A) sequences, and is completely identical to the $A$ cDNA in the region of exons $2-4$, which contain the 131-amino-acid ORF. The $A$ and the $A^{y}$ sequences diverge, however, 10 nucleotides upstream of the putative translational initiation codon (Fig. 5A). Sequence analysis of genomic DNA revealed that the two sequences diverge precisely at the boundary between exons 1 and 2 of the $A$ cDNA and at the exon 2 splice acceptor of the $A^{y}$ cDNA (Fig. 5B).

Within the $5^{\prime}$ sequences specific for $A^{y}$, there are ATGs at positions 272 and 286 that begin ORFs of 9 and 20 amino acids, respectively, but neither of these ATGs is predicted to function as a translational initiation site (Kozak 1989). Instead, the conceptual translation product from the 923-nucleotide $A^{y}$ RNA begins from the first ATG in exon 2 and, therefore, is exactly the same as from the 730 -nucleotide $A$ RNA. The $A^{y}$-specific $5^{\prime}$ se- 


\section{Miller et al.}
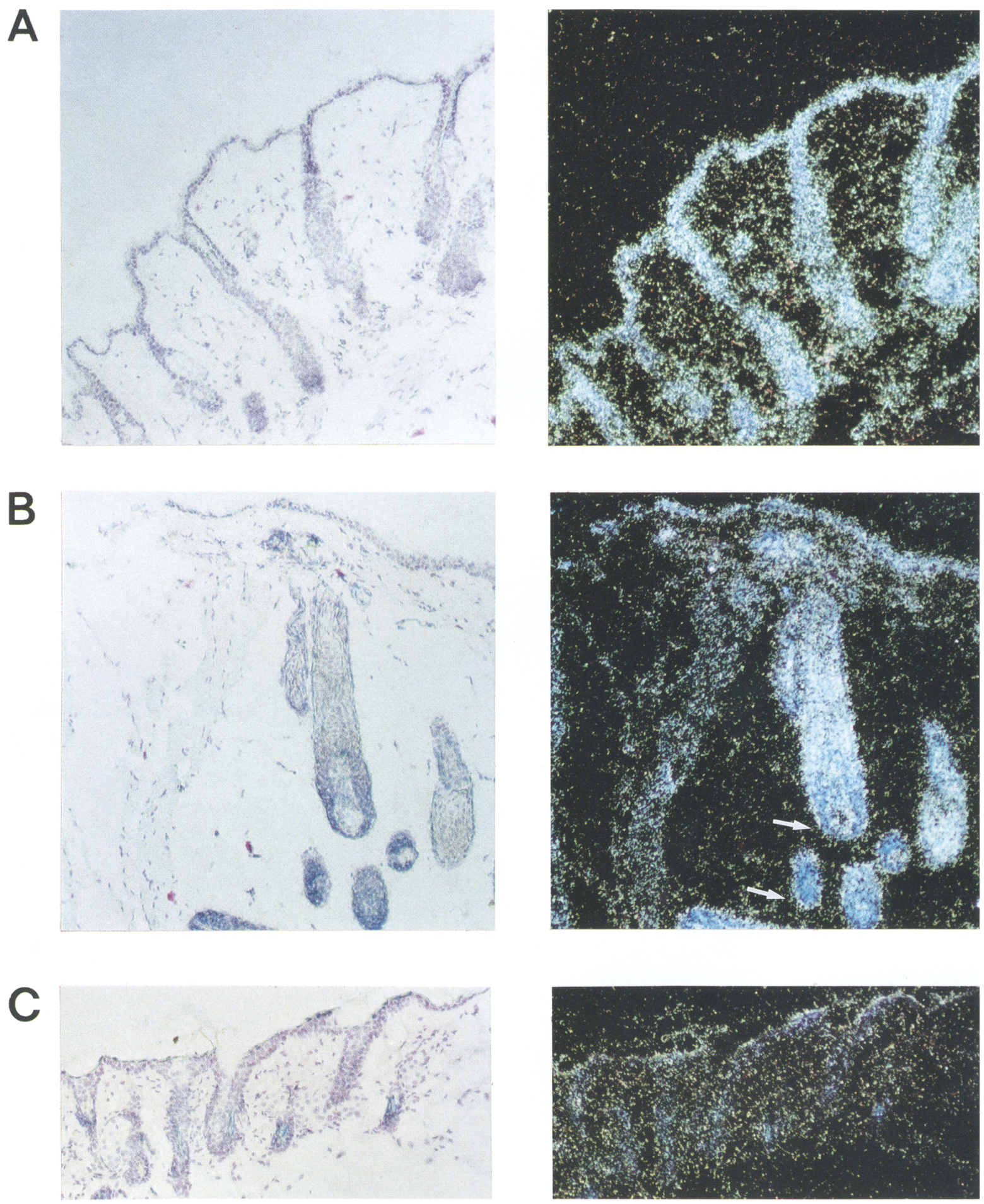

Figure 4. Expression of agouti detected by in situ hybridization of skin sections from $A^{W} / A$ and $A^{y} / a^{x}$ mice. Tissue preparation and hybridization with an agouti-coding region probe are described in Materials and methods. Bright-field and dark-field images of the same sections are shown in left and right panels, respectively. $(A) A^{W} / A$ skin section hybridized to an antisense probe 7 days after plucking. $(B) A^{y} / a^{x}$ skin section hybridized to an antisense probe 7 days after plucking. The pattern of expression is similar in the $A^{W} / A$ and $A^{y} / a^{x}$ sections, and includes epithelial cells of the hair follicles and the epidermis. However, there is reduced expression at the bases of the $A^{y} / a^{x}$ hair follicles compared with the $A^{W} / A$ hair follicles, indicated by arrows. $(C)$ Control $A^{y} / a^{x}$ skin section hybridized to a sense probe 7 days after plucking. 
A

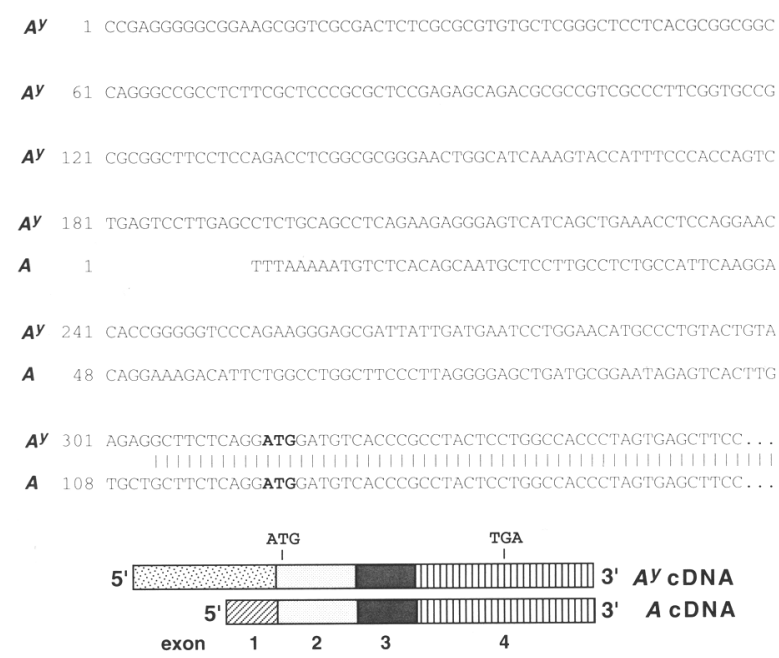

Figure 5. Genomic and cDNA sequence of the $A^{y}$-specific cDNA. (A) The 5' sequences of the $A^{y}$ and $A$ cDNAs. The $A^{y}$ specific 5 ' sequence represents one clone from a cDNA library and nine RACE clones that were identical in the region of overlap. The putative translational initiation codon is indicated in boldface type. Within the $A^{y}$-specific 5' sequences upstream of this codon there are no potential sites for translational initiation (see text). The GenBank accession number for the $A^{y}$-specific $5^{\prime}$ sequence is L06452. $(B)$ Diagram of the normal $A$ and the chimeric $A^{y}$ cDNAs. Novel 5' sequences in the $A^{y}$ cDNA do not affect its protein-coding potential, which is identical to the $A$ cDNA.

quences do not lie within the cosmid contiguous sequence shown in Figure 2A.

Expression of the $\mathrm{A}$ and $\mathrm{A}^{\mathrm{y}} c D N A s$ in different tissues of $\mathrm{A}^{\mathrm{y}} / \mathrm{a}^{\mathrm{x}}$ animals

The $A^{y}$-specific RNA contains novel $5^{\prime}$ sequences, but has the same protein-coding potential as the $A$ RNA. To investigate whether the molecular basis of the $A^{y}$ phenotype might involve ectopic expression of the normal agouti gene product, we hybridized an agouti-coding region probe to RNA from the brain, testes, skin, liver, kidney, lung, and spleen of control and $A^{y} / a^{x}$ animals. An $\sim 0.9-\mathrm{kb}$ band was detected in all $A^{y} / a^{x}$ tissues, but in this size range only the 0.8 -kb band from skin was detected in tissues from $A / A$ or $A^{W} / A$ animals (Fig. 6). To determine whether RNAs from the $A^{y} / a^{x}$ tissues contained $A$ - and/or $A^{y}$-specific $5^{\prime}$ sequences, the membrane was rehybridized with each of these probes. Without exception, the 0.9-kb RNA in all of the $A^{y} / a^{x}$ tissues was detected by a probe from the $A^{y}$-specific $5^{\prime}$ sequences but not by a probe from the $A$-specific $5^{\prime}$ sequences. Conversely, the $0.8-\mathrm{kb}$ RNA in $A / A$ skin was detected by a probe from the $A$-specific 5 ' sequences but not by a probe from the $A^{y}$-specific $5^{\prime}$ sequences (Fig. 6). Besides the small RNAs representing the $A$ and $A^{y}$ cDNAs, the agouti-coding region probe also detected the 6.1-kb RNA represented by the $0252 \mathrm{cDNA}$ (see Fig. 2C) in testes from both $A / A$ and $A^{y} / a^{x}$ animals (Fig. 6).

\section{Discussion}

Morphologic differences among inbred strains of mice represent the premier experimental system for studying genetic variation in mammals. Of seven genes usually included in systematic studies of mutational rates and mechanisms (Russell 1951, 1989), five, not including agouti, have been cloned in the last several years (Kwon et al. 1987; Jackson 1988; Mercer et al. 1991; Gardner et al. 1992; Kingsley et al. 1992). All but one of these genes affect coat color; but in nearly every case, functional or molecular analysis, or both, of each gene has provided insight into many aspects of mammalian growth and development.

Here, we report the molecular cloning of agouti and an analysis of $A^{y}$, the first recognized mouse obesity gene (Danforth 1927; for review, see Herberg and Coleman 1977) and the oldest known embryonic lethal mutation (Cuènot 1908; Castle and Little 1910). The predicted agouti gene product is a small secreted protein that con-

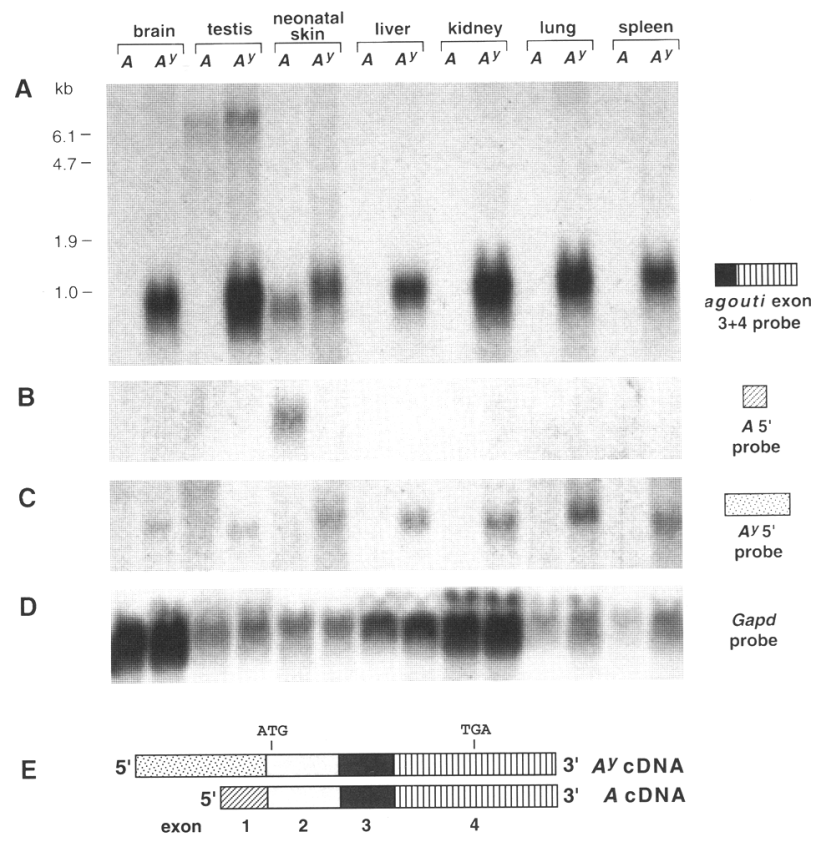

Figure 6. Expression of $A$ - and $A^{y}$-specific sequences detected by Northern hybridization of RNA from different tissues of $A^{w} /$ $A, A / A$, and $A^{y} / a^{x}$ mice. (A) Hybridization with an agouti-coding region probe containing sequences from exons 3 and 4 (nucleotides 284-696 in Fig. 2E). (B) Hybridization with a PCRderived probe specific for the $5^{\prime}$ end of the $A$ cDNA /nucleotides 1-111 in Fig. 2E). (C) Hybridization with a PCR-derived probe specific for the $5^{\prime}$ end of the $A^{y}$ cDNA (nucleotides 120-304 in Fig. 5A). (D) Hybridization with a Gapd housekeeping probe to control for different amounts of RNA loaded on the gel. In lanes $A^{y}$, samples were prepared from $A^{y} / a^{x}$ animals; in lanes $A$, skin and testes samples were prepared from $A / A$ animals, and brain, liver, kidney, lung, and spleen samples were prepared from $A^{W} / A$ animals. The filter shown in $A$ was stripped and rehy. bridized for the image shown in $B$. Duplicate filters prepared with the same samples were used for the images shown in $C$ and $D$. $\{E\}$ Diagram of the normal $A$ and the chimeric $A^{y}$ cDNAs. 
tains a central portion rich in basic amino acids and has a cysteine-rich carboxyl terminus. Our studies demonstrate that for the wild-type alleles $A$ and/or $A^{W}$, agouti RNA is expressed by cells in the hair follicle and epidermis and that increased levels of expression correlate with the synthesis of yellow pigment. In $A^{y} / a^{x}$ mice that are completely yellow, normal agouti sequences have been brought under the control of new regulatory elements. This leads to the ectopic production of an mRNA with a novel $5^{\prime}$ end but that retains the protein-coding capacity of the normal allele. These findings provide insight into mechanisms of pattern formation during hair growth (Galbraith 1964; Granholm et al. 1990a), establish a foundation for a molecular analysis of classic genetic phenomena (Russell et al. 1963; Dickie 1969), and have implications for understanding common disease processes (Wolff 1971; Wolff et al. 1986).

\section{Cloning of the agouti gene and the Is1GsO breakpoint}

We attempted to isolate agouti on the basis of its map position by generating a meiotic map using an intersubspecific backcross and then placing systematically on this map molecular markers recovered from radiationreduced somatic cell hybrids (Cox et al. 1989; Ollmann et al. 1992). Ultimately, these anonymous markers were not as useful as one derived from a chromosomal rearrangement, Is $1 \mathrm{GsO}$, which was first recognized as a radiation-induced agouti mutation (Woychik et al. 1990; Bultman et al. 1991), and which we used to clone the agouti gene.

We found that a genomic probe derived from the distal breakpoint of the Is $1 \mathrm{GsO}$ inversion cosegregated with $A^{y}$ or $a^{x}$ among our recombinant backcross progeny; we then used this probe to identify two mRNAs, 730 nucleotides and $6.1 \mathrm{~kb}$ in length, which have opposite transcriptional orientations and whose $3^{\prime}$ exons are interspersed. Both of these RNAs have coding sequences that are deleted from an amorphic agouti allele, $a^{5 M N U}$, whose physical structure was described by Bultman et al. (1991). However, because agouti expression can be affected by genetically separable cis-acting sequences (Russell et al. 1963; Phillips 1966), and because there are several genes required for embryonic viability closely linked to agouti, physical mapping alone was not sufficient to prove the identity of either of the two mRNAs. Instead, our assertion that the 730-nucleotide mRNA represents the normal agouti gene is based on three findings.

First, the 730-nucleotide RNA, but not the 6.1-kb RNA, is expressed in skin, and our in situ hybridization studies indicate that the 730-nucleotide RNA is expressed directly within a growing hair follicle. Second, the temporal expression pattern of the 730-nucleotide RNA conforms to expectations from genetic and physiologic studies that the agouti gene product should be expressed during or shortly before phaeomelanin synthesis (Galbraith 1964; Sakurai et al. 1975; Silvers 1979). Finally, ectopic expression of normal protein-coding sequences from the $A^{y}$ allele explains how a dominant mu- tation can result in pleiotropy. This last point is especially important because many of the dominant pleiotropic effects seen in $A^{y} /$ - animals are also seen in animals heterozygous for other agouti alleles associated with excess phaeomelanin production (Coleman 1982; Wolff et al. 1986). It will be interesting to determine whether these alleles-viable yellow $\left\langle A^{v y}\right|$, sienna yellow $\left(A^{s y} \mid\right.$, and intermediate yellow $\left(A^{i y}\right)$-also exhibit ectopic expression and/or overexpression of normal agouti proteincoding sequences.

Of the adult tissues we examined, the 6.1-kb mRNA whose $3^{\prime}$ end is represented by the $0252 \mathrm{cDNA}$ clone was expressed only in the testes. Although the sequence of this cDNA does not contain a significant ORF (M.W. Miller, H. Vrieling, and G.S. Barsh, unpubl.), it is possible that the $6.1-\mathrm{kb}$ mRNA represents one of the genes closely linked to agouti that are required for embryonic viability and that define three distinct complementation groups (Barsh and Epstein 1989b).

\section{Is agouti a complex genetic locus?}

Some agouti alleles affect certain regions of the body differently from others. For example, the black-and-tan $\left(a^{t}\right)$ allele produces ventral hairs that are completely yellow but dorsal hairs that are completely black. This has suggested that the agouti phenotype is controlled independently in different body regions, providing support for the hypothesis that agouti is a complex locus composed of several distinct but closely linked genes, one for each part of the body (for summary, see Wallace 1965). Our findings do not support the complex locus theory. Using agouti-coding sequences as a probe, Southern hybridization experiments suggest only a single copy per genome. In addition, among 324 backcross progeny typed for agouti and Emv-15, there were no exceptional animals that might have represented recombination between $A^{y}$ and $A$ or between $a^{x}$ and $A$. In a larger sample of animals, Siracusa and colleagues have described recombination between $A^{y}$ and $a^{x}$, and probable recombination between $A^{y}$ and $a$ or $a^{t}$, indicating a genetic distance between $A^{y}$ and $a^{x}$ of $0.1 \mathrm{cM}$ /Siracusa et al. 1987a; Siracusa 1991). However, because blot hybridization data suggest that there is a chromosomal rearrangement in $A^{y}$ with a breakpoint $\geqslant 50 \mathrm{~kb}$ centromere-proximal of the normal agouti 5' end (Siracusa 1991; D.M.J. Duhl, H. Vrieling, and G.S. Barsh, unpubl.|, recombination between $A^{y}$ and $a^{x}$ is most likely explained by a crossover between $A^{y}$-specific $5^{\prime}$ sequences and agouti-coding sequences.

An alternative explanation for the black-and-tan and white-bellied agouti phenotypes posits the existence of agouti regulatory sequences that respond to region-specific signals. Because phaeomelanin synthesis in whitebellied agouti animals correlates with the level of agouti mRNA, it will be interesting to compare transcriptional regulatory sequences from different alleles and to characterize in more detail the mRNAs produced from different body regions. Preliminary evidence suggests the potential for heterogeneity in the $5^{\prime}$ end of agouti 
cDNAs (H. Vrieling, D.M.J. Duhl, and G.S. Barsh, unpubl.).

\section{Possible physiologic roles of the predicted agouti} gene product

Our structural and gene expression studies may help to understand certain aspects of the agouti signaling process that had been characterized previously at a physiologic level. Skin transplantation experiments have suggested that the switch from eumelanin to phaeomelanin synthesis by follicular melanocytes is triggered by a paracrine factor released from nonmelanocytic cells (Silvers and Russell 1955; Silvers 1958a,b, 1979). The predicted agouti gene product, which contains a putative signal sequence and is expressed by cells in the hair follicle, is a logical candidate for that factor. Sequence similarity searches did not reveal any previously cloned genes that resembled agouti; therefore, it is difficult to speculate about the role of potential domains other than the putative signal sequence. Nonetheless, the high proportion of basic residues in the central region and of cysteine residues in the carboxy-terminal region of the predicted protein are quite striking. Proteins of the corticostatin/defensin family are small basic cysteine-rich peptides that appear to function in the extracellular environment but are not significantly similar to the predicted agouti gene product at the level of primary sequence (Ouellette and Lualdi 1990). Other cysteine-rich proteins found in the hair follicle play a structural and not a signaling role (McNab et al. 1989; MacKinnon et al. 1990).

Dermal-epidermal recombination experiments using tissues from $A^{W} / A^{w}, A / A, a^{t} / a^{t}$, and $a / a$ animals have suggested that agouti phenotypes of these animals are determined by cells of mesodermal origin (Poole 1975; Poole and Silvers 1976). Similar experiments using tissues from $A^{y} / a, A^{v y} / a, A^{S} / A^{S}$, and $a^{m} / a^{m}$ mice suggested that these alleles could act also through epidermal cells (Poole 1975, 1980, 1982; Poole and Silvers 1976). By in situ hybridization, we find expression of agouti RNA in areas of regenerating $A^{W} / A$ hair follicles that include the dermal papilla and the dermal sheath, which are both derived from mesodermal cells. However, we also find generalized expression of agouti RNA in the nonkeratinized epidermis and in the epidermal component of $A^{W} / A$ hair follicles. We do not yet understand why the presence of agouti RNA in the $A^{W} / A$ epidermis might not affect hair phenotype (Poole 1975; Poole and Silvers 1976), although further studies with antibodies directed against the predicted agouti protein product may help to resolve whether an agouti protein is made by epidermal cells of $A^{w} / A$ hair follicles and, if so, whether it is transported to follicular melanocytes.

Although the agouti gene product is likely to act as an extracellular molecule, its effects are consummated by the intracellular conversion of dopaquinone to phaeomelanin in melanocytes (for review, see Hearing and Tsukamoto 1991). This effect is opposite that of $\alpha$-melanocyte-stimulating hormone $(\alpha-\mathrm{MSH})$, which stimulates the conversion of dopaquinone to eumelanin $/ \mathrm{Ge}-$ schwind, 1966; Granholm and Van 1991). Injection of $\alpha$-MSH into the skin of yellow $A^{y /}$ - animals can "override" the agouti signal and produce a darkening of the coat. Interestingly, as with $A^{y /}-$, mice homozygous for the recessive allele $e$ of the mouse extension $(E)$ locus also have hair that contains only phaeomelanin; however, e/e mice are resistant to the actions of $\alpha-\mathrm{MSH}$ (Tamate and Takeuchi 1984). Furthermore, analysis of double mutants indicates that extension is epistatic to agouti (Wolff et al. 1978; Silvers 1979; Tamate and Takeuchi 1984). For these reasons, it has been suggested that agouti may act as a pharmacologic antagonist of $\alpha-\mathrm{MSH}$ and that the $E$ gene may affect the production or coupling of a receptor that binds agouti or $\alpha-\mathrm{MSH}$, or both (Tamate and Takeuchi 1984; Takeuchi et al. 1989). The recent cloning of the melanotropin receptor should allow these hypotheses to be tested (Mountjoy et al. 1992).

\section{The molecular basis of $\mathrm{A}^{y}$ and embryonic lethality}

The 923-nucleotide $A^{y}$-specific RNA that we cloned has a different $5^{\prime}$ end from the $A$ RNA but contains the complete protein-coding region of agouti at its $3^{\prime}$ end. The $A^{y}$ and $A$ sequences diverge precisely at the junction between exons 1 and 2 , and sequences surrounding the $A^{W}$ and $A^{y}$ splice acceptor sites are identical. In addition, a probe from the $5^{\prime}$ sequences specific for $A^{y}$ detects their ubiquitous expression in $A^{y} / a^{x}$ animals but not in $A / A$ animals. Together, these results demonstrate that the $A^{y}$ mutation causes transcriptional activation and splicing of novel 5' sequences to exons 2-4 of the normal $A$ gene.

Surprisingly, 6 of 17 cDNA clones isolated from neonatal skin of $A^{y} / a^{x}$ animals had a $5^{\prime}$ end identical to the 730-nucleotide $A$ cDNA. Because we did not detect this population of cDNAs in Northern hybridization studies of skin from $A^{y} / a^{x}$ or $a^{x} / a$ animals, its disproportionate representation in RACE-derived clones may be related to a difference in secondary structure as there is a lower GC content at the $5^{\prime}$ end of the $A$ cDNA, $48 \%$ across $111 \mathrm{bp}$, compared with the $5^{\prime}$ end of the $A^{y}$ cDNA, $65 \%$ across $304 \mathrm{bp}$. The molecular alterations responsible for the $A^{y}$ and $a^{x}$ mutations do not disturb agouti exons 1-4 (D.M.J. Duhl, M.W. Miller, H. Vrieling, and G.S. Barsh, unpubl.); therefore, an $A$ mRNA might be transcribed at low levels from either the $A^{y}$ or the $a^{x}$ chromosome.

Recessive lethality of $A^{y} / A^{y}$ homozygotes was described in the early 1900s and has been the subject of considerable investigation for many years (Eaton and Green 1963; Calarco and Pederson 1976; Papaioannou and Gardner, 1979; Papaioannou 1988; Barsh et al. 1990). We do not yet know the nature of the event that has led to transcriptional activation of $A^{y}$-specific $5^{\prime}$ sequences, but several lines of evidence suggest that increased expression of agouti, per se, is not responsible for embryonic lethality of $A^{y} / A^{y}$ homozygotes. First, as described above, yellow $A^{v y} /-, A^{s y} /-$, and $A^{i y} /-$ animals are obese, but these alleles are not recessive lethals. Second, genetic studies indicate that $A^{y}$ is neomorphic (gain of function) with regard to coat color, obesity, and tumor 
susceptibility, but amorphic (loss of function) with regard to embryonic viability (Lyon et al. 1985; Barsh and Epstein 1989b). Finally, Siracusa (1991) has reported that a probe from the Parotid secretory protein $(P s p)$ gene, which lies $\sim 1 \mathrm{cM}$ proximal to agouti, detects long-range restriction fragments of abnormal mobility in the $A^{y}$ allele, providing additional evidence for a chromosomal rearrangement in $A^{y}$ with a breakpoint centromere-proximal of agouti $5^{\prime}$-coding sequences. A chromosomal rearrangement that produced transcriptional activation of one gene and an interruption or deletion of another could explain the simultaneous acquisition of both neomorphic and amorphic characteristics in $A^{y}$.

\section{Is agouti part of a general signaling mechanism?}

The molecular basis of $A^{y}$ has implications for the pathogenesis of common disease processes. If agouti is the ligand for a signaling pathway that acts on follicular melanocytes, then activation of the same or a similar signaling pathway in tissues other than the skin is likely to account for the dominant pleiotropic effects of $A^{y}$. In turn, this implies that the receptor, or receptors, to which agouti binds is expressed in nonpigmented tissues and that agouti coat color represents specialization of a general signaling mechanism used throughout the body. It is possible that agouti is expressed in a limited distribution but that its receptor is expressed more broadly. Alternatively, there may be a family of receptors to which agouti can bind, only one of which is expressed in the skin. As described above, both the melanotropin receptor and the product of the $E$ gene are candidates for downstream effectors of agouti. The effects of $E$ mutations are limited to pigmented tissues, but melanotropins can affect many different tissues of the body (Dores 1990; Lipton 1990).

In contrast to two other well-characterized mutations that produce obesity, $o b$ and $d b$, the obesity that develops in $A^{y /}$ - animals begins later in life, is less extensive, and is associated with less glucose intolerance (Coleman 1982; Friedman and Leibel 1992). However, despite extensive study, it is not clear whether the primary events in $A^{y}$-induced obesity are caused by behavioral changes, such as hyperphagia and altered thermoregulation, or by metabolic changes, such as altered lipoprotein metabolism and adipogenesis (Herberg and Coleman 1977; Coleman 1982). The study of additional agouti alleles in combination with the experimental manipulation of agouti expression in transgenic animals will allow these possibilities to be tested.

\section{Materials and methods}

Mouse strains, mutations, and breeding studies

Mice carrying the $A^{y}$ mutation were obtained originally as C57BL/6J $-A^{y} / a$; mice carrying the $a^{x}$ mutation were generously provided by Dr. Virginia Papaioannou (Tufts University School of Medicine, Boston, MA). These alleles were propagated in our laboratory as a balanced lethal stock, $A^{y} / a^{x}$, and occasionally crossed out to $\mathrm{C} 57 \mathrm{BL} / 6 \mathrm{~J}-a / a$ mice to provide a source of $A^{y} / a$ or $a^{x} / a$ tissues. Unless stated otherwise, mice carrying the $A$ allele were from the FVB/N strain and mice carrying the $A^{W}$ allele were from the $129 / \mathrm{Sv}$ J strain. For breeding studies, $M$. castaneus animals of agouti genotype $A / A$ were generously provided by Dr. Verne Chapman (Roswell Park Memorial Institute, Buffalo, NY|. These mice were crossed with $A^{y} / a^{x}$ mice and their Fl progeny backcrossed to $\mathrm{MWT} / \mathrm{Le}-a^{t} / a^{t}$ laboratory mice. Analysis of these backcross progeny for segregation of additional markers surrounding the agouti locus will be described in detail elsewhere (B.M. Winkes, M.M. Ollmann, and G.S. Barsh, in prep.).

\section{DNA probes}

Unique-sequence DNA probes used to analyze backcross progeny include genomic DNA flanking the retroviral insertion sites Emv-13 and Emv-15, and a genomic fragment from the distal inversion breakpoint of the Is $1 \mathrm{GsO}$ chromosome. The $E m v-13$ probe is a $0.6-\mathrm{kb}$ SstI-EcoRI genomic fragment $3^{\prime}$ to the site of retroviral insertion (Copeland et al. 1984) and was generously provided by Drs. Linda Siracusa, Neal Copeland, and Nancy Jenkins (National Cancer Institute, Frederick, MD). The Emv-15 probe is a $1.1-\mathrm{kb}$ EcoRI genomic fragment $3^{\prime}$ to the site of retroviral insertion (Lovett et al. 1987). The Is1GsO probe (Bultman et al. 1991) is part of a cosmid, cos 12, isolated from the mouse strain 129/R1, generously provided by Dr. R.P. Woychik (Oak Ridge National Laboratory, Oak Ridge, TN).

\section{Genomic and cDNA cloning and sequence analysis}

We generated a $60-\mathrm{kb}$ cosmid contig surrounding the distal inversion breakpoint of Is $1 \mathrm{GsO}$ in two rounds of genomic cloning. The BamHI and EcoRI restriction map of $\cos 12$ was first determined by indirect end-labeling; unique-sequence terminal probes were then used to isolate $\cos \mathrm{Dl}$ and $\cos \mathrm{D} 2$; and finally, a terminal probe from $\cos \mathrm{D} 2$ was used to isolate $\cos \mathrm{D} 3$ (see Fig. $2 \mathrm{~A}) \cdot \cos \mathrm{D} 1, \cos \mathrm{D} 2$, and $\cos \mathrm{D} 3$ were isolated from a library prepared from $A^{y} / a^{x}$ DNA using partial digestion with Sau3A and the vector Scos. Identification of restriction fragment length variants between $A^{y}$ and $a^{x}$ alleles allowed us to determine that both $\cos \mathrm{D} 1$ and $\cos \mathrm{D} 2$ originated from the $A^{y}$ allele (data not shown).

To isolate the $A$ and $A^{y}$ cDNA clones, we used polyadenylated skin RNA from 5 -day-old neonatal $A / A$ and $A^{y} / a^{x}$ mice. cDNA libraries containing $\sim 10^{6}$ primary plaques were constructed using Moloney murine leukemia virus reverse transcriptase and an oligo(dT) primer/adapter in the vector $\lambda$ ZAPII (Stratagene). A commercial cDNA library (Stratagene) constructed from testes RNA of random-bred CD-1 mice was the source of the 0252 cDNA; four clones that contained agouti exons 2-4 were also recovered from this library. Probes b, c, and d (see Fig. 2D) or a protein-coding region probe generated by PCR (nucleotides 284-696 of the $A$ cDNA; Fig. 2E) were used to screen the libaries. Probe $b$ is a PCR-derived 500-bp genomic fragment that contains all but 2 nucleotides of agouti exon 3 (nucleotides 284-347; Fig. 2E); the 3' end of probe b was amplified with the primer $5^{\prime}$-ATTCTCAGCACTCCGGGG-3'. Probe $\mathrm{c}$ is a $0.9-\mathrm{kb}$ BamHI-XbaI genomic fragment that lies between agouti exons 3 and 4 . Probe $\mathrm{d}$ is a $1.0-\mathrm{kb} X b a \mathrm{I}-E c o R I$ genomic fragment that contains agouti exon 4 . The locations of these probes are indicated in Figure 2D.

Additional cDNA clones were derived using a PCR-based protocol for the "rapid amplification of cDNA ends" (RACE; Frohman et al. 1988) and a commercial kit (BRL). Using the same RNA source as for the libraries, polyadenylated skin RNA of 5-day-old neonatal $A / A$ and $A^{y} / a^{x}$ mice, cDNA was made with 
a primer from exon 3 of the $A$ cDNA, 5'-GAAACGGCACTGGCAGGAGG-3', digested with RNase $H$, and then tailed with oligo(dC). A first round of PCR for 30 cycles was performed using the commercial dG- and dI-containing "anchor primer" and an internal primer from exon 3, 5'-GGATTTCTTGTTCAGTGCCACG-3', that had been biotinylated. DNA that contained the biotinylated primer was purified using streptavidincoated magnetic beads (Promega), and a second round of PCR was then performed for 30 cycles with a commercial adapter/ primer and a third internal primer, 5'-CGAGTTCATGGAGGAGTTACTCCGC-3'. This mixture of PCR products was inserted into a plasmid vector, and positive clones were identified by colony hybridization using a probe specific for agouti exon 2 . Of the nine independent clones that represent the $A$ cDNA, 2 were isolated from the $A / A$ cDNA library and seven were derived using the RACE protocol. The two skin library cDNA clones and the five clones isolated by RACE were identical in the region of overlap. However, the cDNA clones isolated from a commercial cDNA library prepared from CD-1 testes RNA contained a $G$ instead of an A at nucleotide position 158. This difference would result in a Ser $\rightarrow$ Gly substitution in a portion of the predicted protein that conforms to a putative signal sequence and may represent a neutral polymorphism. In addition, two RACE-derived clones, isolated from skin RNA of FVB/N animals, contained a $\mathrm{C}$ instead of a $\mathrm{T}$ at position 165. Because the RACE-derived clones were isolated from skin RNA of the FVB/N inbred strain, this difference may have resulted from errors during reverse transcription or PCR. Several additional sequence variants were encountered during analysis of individual RACE clones, but these were assumed to be PCR artifacts as the same variant was never encountered more than once. Of the 10 clones that represent the $A^{y}$ cDNA, 1 was isolated from the $A^{y} / a^{x}$ cDNA library and 9 were derived using the RACE protocol. In the region of overlap, these clones were identical to the $A$ cDNA-coding sequences.

Northern and Southern hybridizations and DNA sequence analysis using modified $\mathrm{T} 7$ polymerase and dideoxy chain termination were performed according to standard techniques using radiolabeled nucleotides and hybridization in the presence of $10 \%$ dextran sulfate.

\section{Expression studies}

For RNA blots, total RNA was prepared from dissected organs of adult animals and then separated on formaldehyde gels according to standard techniques. For RNA and tissue sections from plucked adult skin, hair from anesthetized animals was manually removed from an $\sim 5 \times 5-\mathrm{cm}$ area (for RNA purification) or an $\sim 2 \times 0.5-\mathrm{cm}$ area (for tissue sections). Skin fragments were dissected free of underlying tissues, fixed in buffered isotonic $4 \%$ paraformaldhyde for $\geqslant 24 \mathrm{hr}$, dehydrated through graded alcohol solutions, and then stored in absolute ethanol. Paraffinembedded sections of $8 \mu \mathrm{g}$ were transferred to 3-aminopropyltriethoxysilane-coated slides and stored at $4^{\circ} \mathrm{C}$.

For in situ hybridization, cDNA fragments that contained 194 nucleotides of agouti sequences (nucleotides 122-146 and 377547; see Fig. 2E) from exons 2-4 were cloned in the vector pBluescript II (Stratagene). In vitro transcription with a $\alpha{ }^{35} \mathrm{~S}-1 \mathrm{a}-$ beled UTP, followed by alkaline hydrolysis, was used to produce radiolabeled antisense and control sense probes. Specimens were hybridized and washed according to Frohman et al. (1990), dehydrated in graded alcohols, air-dried, and covered with Kodak NTB2 emulsion. After 7-10 days of exposure, the specimens were developed and counterstained with toluidine blue. Photographs were taken by single exposure in bright or dark field using a Nikon Microphot-FXA microscope.

\section{Acknowledgments}

M.W.M., D.M.D., and H.V. contributed equally to this work and the order of these authors is arbitrary. We are grateful to members of the Kingsley and Nusse research groups for their advice and helpful comments. We thank Verne Chapman for providing the $M$. castaneus animals and Virginia Papaioannou for providing animals carrying the $a^{x}$ allele. We thank Scott Bultman and Rick Woychik for providing the IsIGsO probe, and Linda Siracusa, Nancy Jenkins, and Neal Copeland for providing the Emv13 probe. This work was supported in part by grant HG-00377 from the National Institutes of Health. S.P.C. is supported by a grant from the American Cancer Society, and H.V. is supported by the J.A. Cohen Institute, Leiden, The Netherlands. G.S.B. is an Assistant Investigator of the Howard Hughes Medical Institute.

The publication costs of this article were defrayed in part by payment of page charges. This article must therefore be hereby marked "advertisement" in accordance with 18 USC section 1734 solely to indicate this fact.

\section{References}

Barsh, G.S. and C.J. Epstein. 1989a. The long-range restriction map surrounding the mouse agouti locus reveals a disparity between physical and genetic distances. Genomics 5: 9-18.

- 1989b. Physical and genetic characterization of a 75kilobase deletion asssociated with $a^{I}$, a recessive lethal allele at the mouse agouti locus. Genetics 121: 811-818.

Barsh, G.S., M. Lovett, and C.J. Epstein. 1990. Effects of the lethal yellow $\left(A^{y}\right)$ mutation in mouse aggregation chimeras. Development 109: 683-690.

Bultman, S.J., L.B. Russell, G.A. Gutierrez-Espeleta, and R.P. Woychik. 1991. Molecular characterization of a region of DNA associated with mutations at the agouti locus in the mouse. Proc. Nat1. Acad. Sci. 88: 8062-8066.

Calarco, P.G. and R.A. Pederson. 1976. Ultrastructural observations of lethal yellow $\left(A^{y} / A^{y}\right)$ mouse embryos. I. Embryol. Exp. Morphol. 35: 73-80.

Carpenter, K.J. and J. Mayer. 1958. Physiologic observations on yellow obesity in the mouse. Am. I. Physiol. 193: 499-504.

Castle, W.E. 1941. Influence of certain coat color mutations on body size in mice, rats, and rabbits. Genetics 26: 177-191.

Castle, W.E. and C.C. Little. 1910. On a modified Mendelian ratio among yellow mice. Science 32: 868-870.

Cattanach, B.M., M.F. Lyon, J. Peters, and A.G. Searle. 1987. agouti locus mutations at Harwell. Mouse News Lett. 77: $123-125$.

Coleman, D.L. 1982. Diabetes-obesity syndromes. In The mouse in biomedical research IV (ed. H.L. Foster, J.D. Small, and J.G. Fox), pp. 125-132. Academic Press, New York.

Copeland, N.G., N.A. Jenkins, and B.K. Lee. 1983. Association of the lethal yellow $\left(A^{y}\right)$ coat color mutation with a ecotropic murine leukemia virus genome. Proc. Natl. Acad. Sci. 80: 247-249.

Copeland, N.G., H.G. Bedigian, D.Y. Thomas, and N.A. Jenkins. 1984. DNAs of two molecularly cloned endogenous ecotropic proviruses are poorly infectious in DNA transfection assays. J. Virol. 49: 437-444.

Cox, D.R., C.A. Pritchard, E. Uglum, D. Casher, J. Kobori, and R.M. Myers. 1989. Segregation of the Huntington disease region of human chromosome 4 in a somatic cell hybrid. Genomics 4: 397-407.

Cuènot, L. 1908. Sur quelques anomalies apparentes des proportions Mendeliennes. Arch. Zool. Exp. Gen. 9: 7-15.

Danforth, C.H. 1927. Hereditary adiposity in mice. J. Hered. 
18: $153-162$.

Deringer, M.K. 1970. Influence of the lethal yellow $\left(A^{y}\right)$ gene on the development of reticular neoplasms. I. Natl. Cancer Inst. 45: $1205-1210$.

Dickie, M.M. 1969. Mutations at the agouti locus in the mouse. J. Hered. 60: 20-25.

Dores, R.M. 1990. The proopiomelanocortin family. Prog. Clin. Biol. Res. 342: 22-27.

Eaton, G.J. and M.M. Green. 1962. Implantation and lethality of the yellow mouse. Genetica 33: 106-112.

- 1963. Giant cell differentiation and lethality of homozygous yellow mouse embryos. Genetica 34: 155-161.

Epstein, D.J., M. Vekemans, and P. Gros. 1991. Splotch $\left(S p^{2 H}\right)$, a mutation affecting development of the mouse neural tube, shows a deletion within the paired homeodomain of Pax-3. Cell 67: 767-774.

Friedman, J.M. and R.L. Leibel. 1992. Tackling a weighty problem. Cell 69: 217-220.

Frohman, M.A., M.K. Dush, and G.R. Martin. 1988. Rapid production of full-length cDNAs from rare transcripts: Amplification using a single gene-specific oligonucleotide primer. Proc. Nat1. Acad. Sci. 85: 8998-9002.

Frohman, M.A., M. Boyle, and G.R. Martin. 1990. Isolation of the mouse Hox-2.9 gene: Analysis of embryonic expression suggests that positional information along the anterior-posterior axis is specified by mesoderm. Development 110: 589-607.

Galbraith, D.B. 1964. The agouti pigment pattern of the mouse: A quantitative and experimental study. J. Exp. Zool. 155: 71-90.

Gardner, J.M., Y. Nakatsu, Y. Gondo, S. Lee, M.F. Lyon, R.A. King, and M.H. Brilliant. 1992. The mouse pink-eyed dilution gene: Association with human Prader-Willi and Angelman syndromes. Science 257: 1121-1124.

Geissler, E.N., M.A. Ryan, and D.E. Housman. 1988. The dominant-white spotting (W) locus of the mouse encodes the c-kit proto-oncogene. Cell 55: 185-192.

Geschwind, I.I. 1966. Change in hair color in mice induced by injection of $\alpha \mathrm{MSH}$. Endocrinology 79: 1165-1167.

Granholm, N.H. and A.A. Van. 1991. Effects of exogenous MSH on the transformation from phaeo- to eumelanogenesis within C57BL/6J- $A^{y} / a$ hairbulb melanocytes. I. Invest. Dermatol. 96: 78-84.

Granholm, N.H., R.A. Japs, and K.E. Kappenman. 1990a. Differentiation of hairbulb pigment cell melanosomes in compound agouti and albino locus mouse mutants $\left(A^{y}, a, c^{2 I}\right.$; C57BL/6J). Pigment Cell Res. 3: 16-27.

Granholm, N.H., A.J. Opbroek, G.A. Harvison, and K.E. Kappenman. 1990b. Tyrosinase activity (TH, DO, PAGE-defined isozymes) and melanin production in regenerating hairbulb melanocytes of lethal yellow $\left(A^{y} / a\right)$, black $(a / a)$, agouti $\left(A^{W I} / A^{W J}\right)$ and albino $\left(a / a c^{2 I} / c^{2 I}\right)$ mice $(\mathrm{C} 57 \mathrm{BL} / 6 \mathrm{~J})$. Pigment Cell Res. 3: 233-242.

Green, E.L. 1981. Genetics and probability in animal breeding experiments. Oxford University Press, New York.

Hearing, V.J. and K. Tsukamoto. 1991. Enzymatic control of pigmentation in mammals. FASEB I. 5: 2902-2909.

Hellerström, C. and B. Hellman. 1963. The islets of Langerhans in yellow obese mice. Metabolism 12: 527-536.

Herberg, L. and D.L. Coleman. 1977. Laboratory animals exhibiting obesity and diabetes syndromes. Metabolism 26: 5999.

Heston, W.E. 1942. Relationship between the lethal yellow $\left|A^{y}\right|$ gene of the mouse and susceptibility to induced pulmonary tumors. J. Natl. Cancer Inst. 3: 303-308.

Heston, W.E. and M.K. Deringer. 1947. Relationship between the lethal yellow $\left(A^{y}\right)$ gene of the mouse and susceptibility to spontaneous pulmonary tumors. J. Natl. Cancer Inst. 7: 463-465.

Heston, W.E. and G. Vlahakis. 1961. Influence of the $A^{y}$ gene on mammary-gland tumors, hepatomas, and normal growth in mice. I. Natl. Cancer Inst. 26: 969-982.

Huang, E., K. Nocka, D.R. Beier, T.Y. Chu, J. Buck, H.W. Lahm, D. Wellner, P. Leder, and P. Besmer. 1990. The hematopoietic growth factor KL is encoded by the $S 1$ locus and is the ligand of the c-kit receptor, the gene product of the $\mathrm{W}$ locus. Cell 63: 225-233.

Jackson, I.J. 1988. A cDNA encoding tyrosinase-related protein maps to the brown locus in mouse. Proc. Natl. Acad. Sci. 85: 4392-4396.

Kingsley, D.M., A.E. Bland, J.M. Grubber, P.C. Marker, L.B. Russell, N.G. Copeland, and N.A. Jenkins. 1992. The mouse short ear skeletal morphogenesis locus is associated with defects in a bone morphogenetic member of the TGF $\beta$ superfamily. Cell 71: 399-410.

Kozak, M. 1989. The scanning model for translation: An update. J. Cell. Biol. 108: 229-241.

Kwon, B.S., A.K. Haq, S.H. Pomerantz, and R. Halaban. 1987. Isolation and sequence of a cDNA clone for human tyrosinase that maps at the mouse $c$-albino locus. Proc. Natl. Acad. Sci. 84: 7473-7477.

Lipton, J.M. 1990. Modulation of host defense by the neuropeptide alpha-MSH. Yale I. Biol. Med. 63: 173-182.

Lovett, M., Z.Y. Cheng, E.M. Lamela, T. Yokoi, and C.J. Epstein. 1987. Molecular markers for the agouti coat color locus of the mouse. Genetics 115: 747-754.

Lyon, M.F., G. Fisher, and P.H. Glenister. 1985. A recessive allele of the mouse agouti locus showing lethality with yellow, $A^{y}$. Genet. Res. 46: 95-99.

MacKinnon, P.J., B.C. Powell, and G.E. Rogers. 1990. Structure and expression of genes for a class of cysteine-rich proteins of the cuticle layers of differentiating wool and hair follicles. $J$. Cell. Biol. 111: 2587-2600.

McNab, A.R., L. Wood, N. Theriault, T. Gierman, and G. Vogeli. 1989. An ultra-high sulfur keratin gene is expressed specifically during hair growth. J. Invest. Dermatol. 92: 263266.

Mercer, J.A., P.K. Seperack, M.C. Strobel, N.G. Copeland, and N.A. Jenkins. 1991. Novel myosin heavy chain encoded by murine dilute coat colour locus. Nature 349: 709-713.

Morse, H.C. 1981. The laboratory mouse-A historical perspective. In The mouse in biomedical research led. H.L. Foster J.D. Small, and J.G. Fox), pp. 1-16. Academic Press, New York.

Mountjoy, K.G., L.S. Robbins, M.T. Mortrud, and R.D. Cone. 1992. The cloning of a family of genes that encode the melanocortin receptors. Science 257: 1248-1251.

Movaghar, M. and D.M. Hunt. 1987. Tyrosinase activity and the expression of the agouti gene in the mouse. J. Exp. Zool. 243: 473-480.

Ollmann, M.M., B.M. Winkes, and G.S. Barsh. 1992. Construction, analysis, and application of a radiation hybrid mapping panel surrounding the mouse agouti locus. Genomics 13: 731-740.

Ouellette, A.J. and J.C. Lualdi. 1990. A novel mouse gene family coding for cationic, cysteine-rich peptides. Regulation in small intestine and cells of myeloid origin. J. Biol. Chem. 265: 9831-9837.

Papaioannou, V.E. 1988. Investigation of the tissue specificity of the lethal yellow $\left(A^{y}\right)$ gene in mouse embryos. Dev. Genet. 9: 155-165.

Papaioannou, V.E. and R.L. Gardner. 1979. Investigation of the 
lethal yellow $\left(A^{y} / A^{y}\right)$ embryo using mouse chimaeras. $J$. Embryol. Exp. Morphol. 52: 153-163.

Papaioannou, V.E. and H. Mardon. 1983. Lethal nonagouti $\left(a^{x}\right)$ : Description of a second embryonic lethal at the agouti locus. Dev. Genet. 4: 21-29.

Phillips, R.J.S. 1966. A cis-trans position effect at the $A$ locus of the house mouse. Genetics 54: 485-495.

Poole, T.W. 1975. Dermal-epidermal interactions and the action of alleles at the agouti locus in the mouse. Dev. Biol. 42: 203-210.

1980. Dermal-epidermal interactions and the action of alleles at the agouti locus in the mouse. II. The viable yellow $\left(A^{v y}\right)$ and mottled agouti $\left(a^{m}\right)$ alleles. Dev. Biol. 80: 495-500.

1982. The agouti suppressor $\left(A^{S}\right)$ coat color mutation in mice: Developmental effects on the expression of agouti locus alleles. J. Exp. Zool. 220: 57-64.

Poole, T.W. and W.K. Silvers. 1976. The development of regional pigmentation patterns in black and tan $\left(a^{t}\right)$ mice. $I$. Exp. Zool. 197: 115-119.

Russell, L.B. 1989. Functional and structural analyses of mouse genomic regions screened by the morphological specific-locus test. Mutation Res. 212: 23-32.

Russell, L.B., M.N.C. McDaniel, and F.N. Woodiel. 1963. Crossing over within a "locus" of the mouse. Genetics 48: 907.

Russell, W.L. 1951. X-ray-induced mutations in mice. Cold Spring Harbor Symp. Quant. Biol. 16: 327-336.

Sakurai, T., H. Ochia, and T. Takeuchi. 1975. Ultrastructural change of melanosomes associated with agouti pattern formation in mouse hair. Dev. Biol. 47: 466-471.

Searle, A.G. 1968. Comparative genetics of coat color in mammals. Academic Press, New York.

Silvers, W.K. 1958a. An experimental approach to action of genes at the agouti locus in the mouse. II. Transplants of newborn $a a$ ventral skin to $a^{t} a, A^{w} a, A-$, and $a a$ hosts. $J$. Exp. Zool. 137: 181-188.

- 1958b. An experimental approach to action of genes at the agouti locus in the mouse. III. Transplants of newborn $A^{W_{-}}, A-$, and $a^{t}-$ skin to $A^{y}-, A^{W_{-}}, A_{-}$, and $a a$ hosts. $J$. Exp. Zool. 137: 189-196.

. 1979. The agouti and extension series of alleles, umbrous and sable. In The coat colors of mice, pp. 6-44. Springer-Verlag, New York.

Silvers, W.K. and E.S. Russell. 1955. An experimental approach to action of genes at the agouti locus in the mouse. I. Exp. Zool. 130: 199-220.

Siracusa, L.D. 1991. Genomic organization and molecular genetics of the agouti locus in the mouse. Ann. N.Y. Acad. Sci. 642: 419-430.

Siracusa, L.D., L.B. Russell, E.M. Eicher, D.J. Corrow, N.G. Copeland, and N.A. Jenkins. 1987a. Genetic organization of the agouti region of the mouse. Genetics 117: 93-100.

Siracusa, L.D., L.B. Russell, N.A. Jenkins, and N.G. Copeland. $1987 \mathrm{~b}$. Allelic variation within the Emv-15 locus defines genomic sequences closely linked to the agouti locus on mouse chromosome 2. Genetics 117: 85-92.

Siracusa, L.D., A.M. Buchberg, N.G. Copeland, and N.A. Jenkins. 1989. Recombinant inbred strain and interspecific backcross analysis of molecular markers flanking the murine agouti coat color locus. Genetics 122: 669-679.

Takeuchi, T., T. Kobunai, and H. Yamamoto. 1989. Genetic control of signal transduction in mouse melanocytes. $J$. Invest. Dermatol. (suppl. 5) 92: 193S-242S.

Tamate, H.B. and T. Takeuchi. 1984. Action of the $e$ locus of mice in the response of phaeomelanic hair follicles to alphamelanocyte stimulating hormone in vitro. Science 224: 1241-1242.
Vlahakis, G. and W.E. Heston. 1963. Increase of induced skin tumors in the mouse by the lethal yellow gene $\left(A^{y}\right)$. J. Natl. Cancer Inst. 31: 189-195.

von Heijne, G. 1985. Signal sequences. The limits of variation. J. Mol. Biol. 184: 99-105.

- 1986. A new method for predicting signal sequence cleavage sites. Nucleic Acids Res. 14: 4683-4690.

Wallace, M.E. 1965. Pseudoallelism at the agouti locus in the mouse. I. Hered. 56: 267-271.

Wolff, G.L. 1971. Genetic modification of homeostatic regulation in the mouse. Am. Nat. 105: 241-252.

Wolff, G.L., D.B. Galbraith, O.E. Domon, and J.M. Row. 1978. Phaeomelanin synthesis and obesity in mice. Interaction of the viable yellow $\left(A^{v y}\right)$ and sombre $\left(E^{s o}\right)$ mutations. $J$. Hered. 69: 295-298.

Wolff, G.L., D.W. Roberts, and D.B. Galbraith. 1986. Prenatal determination of obesity, tumor susceptibility, and coat color pattern in viable yellow $\left(A^{v y} / a\right)$ mice. The yellow mouse syndrome. I. Hered. 77: 151-158.

Woychik, R.P., W.M. Generoso, L.B. Russell, K.T. Cain, N.L. Cacheiro, S.J. Bultman, P.B. Selby, M.E. Dickinson, B.L. Hogan, and J.C. Rutledge. 1990. Molecular and genetic characterization of a radiation-induced structural rearrangement in mouse chromosome 2 causing mutations at the limb deformity and agouti loci. Proc. Natl. Acad. Sci. 87: 25882592. 


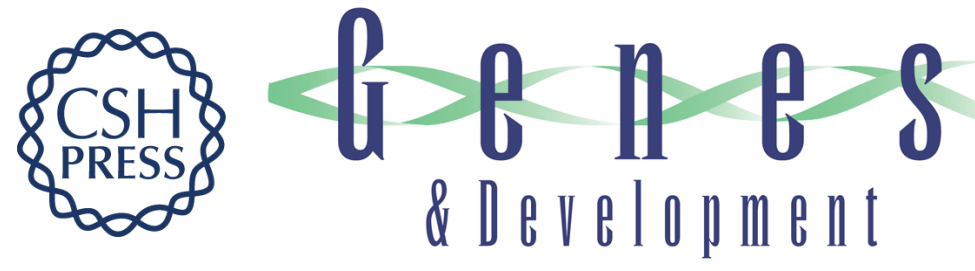

\section{Cloning of the mouse agouti gene predicts a secreted protein ubiquitously expressed in mice carrying the lethal yellow mutation.}

M W Miller, D M Duhl, $H$ Vrieling, et al.

Genes Dev. 1993, 7:

Access the most recent version at doi:10.1101/gad.7.3.454

References This article cites 80 articles, 23 of which can be accessed free at:

http://genesdev.cshlp.org/content/7/3/454.full.html\#ref-list-1

License

Email Alerting

Service

Receive free email alerts when new articles cite this article - sign up in the box at the top right corner of the article or click here.

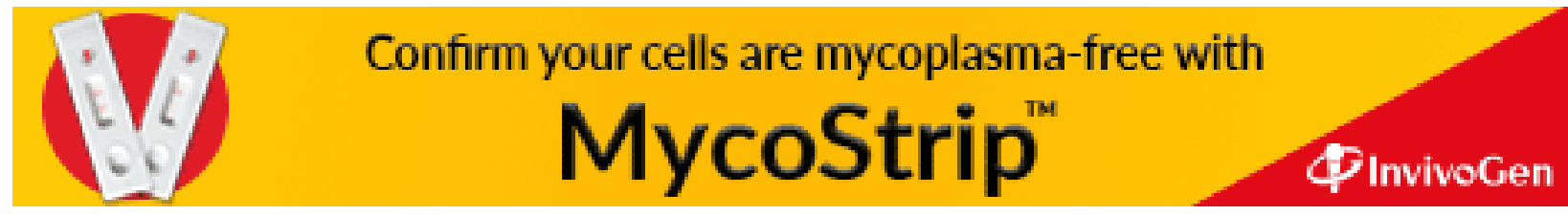

